\title{
Trends in longer-term survival following an acute myocardial infarction and prescribing of evidenced-based medications in primary care in the UK from 1991: a longitudinal population-based study
}

\author{
Sarah L Hardoon, ${ }^{1}$ Peter H Whincup, ${ }^{2}$ Irene Petersen, ${ }^{1}$ Simon Capewell, ${ }^{3}$ \\ Richard W Morris ${ }^{1}$
}

- An additional table is published online only. To view these files please visit the journal online (http://jech.bmj. com).

${ }^{1}$ Department of Primary Care and Population Health, University College London, London, UK

${ }^{2}$ Division of Community Health Sciences, St George's University of London, London, UK

${ }^{3}$ Division of Public Health, University of Liverpool, Liverpool, UK

\section{Correspondence to}

Sarah Hardoon, Department of Primary Care and Population Health, Division of Population Health, UCL Medical School, Royal Free Campus, Rowland Hill Street, London NW3 2PF. UK; s.hardoon@ucl.ac.uk

Accepted 26 February 2010 Published Online First

1 June 2010

\section{UNLOCKA}

This paper is freely available online under the BMJ Journals unlocked scheme, see http:// jech.bmi.com/site/about/ unlocked.xhtml

\begin{abstract}
Background Both the incidence of myocardial infarction (MI) and short-term case fatality have declined in the UK. However, little is known about trends in longer-term survival following an $\mathrm{Ml}$. The aim of the study was to investigate trends in longer-term survival, alongside trends in medication prescribing in primary care.

Methods Data came from 218 general practices contributing to the Health Improvement Network, a UK-wide primary care database. 3-year survival and medication use were determined for 6586 men and 3766 women who had an Ml between 1991 and 2002 and had already survived 3 months.
\end{abstract}

Results Adjusting for age and gender, the 3-year post$\mathrm{Ml}$ case-fatality rate among 3-month survivors fell by 28\% (95\% Cl 13 to 40), from 83 deaths per 1000 personyears for Ml occurring in 1991-2 to 61 deaths per 1000 person-years for Ml in 2001-2. Relative declines in the case-fatality rate of $37 \%(20$ to 50$)$ and $14 \%$ (-11 to 34$)$ were observed for men and women, respectively ( $p=0.06$ for interaction). Prescribing in the 3 months following the Ml of lipid-regulating drugs increased from $3 \%$ of patients in 1991 to $79 \%$ in 2002, prescribing of beta-blockers increased from $26 \%$ to $68 \%$, prescribing of ACE inhibitors increased from $11 \%$ to $71 \%$ and prescribing of anti-platelet medication increased from $46 \%$ to $86 \%$.

Conclusion There has been a moderate improvement in longer-term survival following an $\mathrm{Ml}$, distinct from improvements in short-term survival, although men may have benefited more than women. Increased medication prescribing in primary care may be a contributing factor.

There has been a considerable decline in mortality from coronary heart disease (CHD) in recent decades in the UK. ${ }^{1}$ This is in line with CHD mortality declines in western Europe and the USA, ${ }^{1}$ although in other major regions CHD mortality is increasing. ${ }^{23}$ Despite the decline, CHD remains the leading cause of death in the UK. The decline in CHD mortality may be attributable to a decline in $\mathrm{CHD}$ incidence, or to improved survival of patients with CHD, or a combination of the two. Previous studies suggest that there has been a considerable decline in the incidence of myocardial infarction (MI), the dominant manifestation of $\mathrm{CHD}$, which may be responsible for a large portion of the associated decline in mortality. ${ }^{4-7}$ Concurrent contributing declines in the UK in short-term case fatality (up to 28 days or before discharge from hospital) have also been reported. ${ }^{1} 48$ However, trends in longer-term survival following an $\mathrm{MI}$ in the UK are less well documented. Although one earlier report has suggested that longer-term survival had improved in the UK (specifically in Scotland), ${ }^{8}$ this report included events only up to 1995. There is a lack of data on more recent trends. Moreover, analyses of temporal trends in longerterm survival in other populations often include survival in the short-term in the longer-term survival estimates. It is not clear, therefore, whether the reported decline in long-term fatality reflects almost solely the declines in immediate case fatality, or whether there are additional distinct longer-term declines. Patients with a history of MI, having survived the previous MI, accounted for almost $40 \%$ of out-of-hospital CHD deaths between 1983 and 1997 in the FINAMI study, ${ }^{9}$ emphasising the importance of longer-term survival from MI beyond the immediate period after the MI, on reducing overall population $\mathrm{CHD}$ mortality.

The objective of this study, therefore, was to investigate recent UK-wide time trends, between 1991 and 2005, in longer-term survival following an MI, among men and women who had already survived a 3-month period after the MI. Concurrent trends prescribing of evidenced-based medication in primary care up to 3 months following the MI event were also explored.

\section{METHODS}

\section{THIN data}

The Health Improvement Network (THIN) $)^{10}$ database is a UK-wide general practice database comprising computerised anonymised longitudinal patient records retrieved from more than 300 participating general practitioners (GPs) across the UK. Demographic information as well as all medical diagnoses and prescriptions made at every GP visit are recorded. Data are continuously collected and updated. Each patient is assigned a follow-up start date, as the latest of two possible dates: (1) the date that the patient registered at a contributing GP and (2) the date by which both the practice was fully using their computer system for recording of diagnoses and prescriptions (an average of at least one medical diagnosis, two prescriptions and one additional health data, eg, a blood pressure measurement, recorded per patient per year), and computerised recording of patient 
death (the principal outcome) for the practice had reached an acceptable level. Recording of deaths in the practice was deemed to have reached an acceptable level when the observed number of deaths in the practice first matched the expected number of deaths for that time period, given the age-gender distribution of the practice (using the 'acceptable mortality rate date' as defined by the database providers). ${ }^{11}$ As a further data quality control, only practices with at least 5 years worth of data were included in the analyses (218 practices). The data used for this study cover a 15-year period from 1 January 1991 to 31 December 2005.

\section{Study sample}

The study sample consisted of all patients in the participating practices who had had a diagnosis of MI between 1991 and 2002 inclusive, and who were aged 35 years or over at the time of the MI. Only patients with an MI before 31 December 2002 were included to ensure an equal 3 years potential follow-up for all subjects. A patient was identified as having had an MI if the GP had recorded a diagnosis of MI in the patient's records. Medical diagnoses in THIN GPs are recorded using Read codes, which are a clinical classification system of diagnoses, symptoms and history widely used in UK computerised GP records. ${ }^{12} \mathrm{We}$ identified all Read codes that referred to acute MI or to an ECG result corresponding to an MI, based on previously published code lists. ${ }^{13}$ The earliest record of an MI diagnosis was retained for each patient and the patient was only included if this MI occurred at least 12 months after the patient start date. This ensured that the dataset was consistent across all calendar years in being limited to those patients who had not had another MI in the previous year.

\section{Principal outcome}

The principal outcome was death within 3 years of the MI, given that the patient had survived to 3 months. A patient was identified as having died if their registration status was 'death' or they had a medical diagnosis with a Read code that referred to death of the patient or they had an additional health data code referring to death. The date of death was given with the death record. The survival period was chosen a priori. Three months was chosen as a start date as the outcome of interest was longerterm survival, once a patient has survived the immediate higherrisk interval after the MI, ensuring as far as possible that the patient has been discharged from the initial hospitalisation. Three months also allowed enough time for medication use to be assessed before the start date of the follow-up for the outcome (see below), leading to a fairer comparison between the medication and survival trends.

\section{Assessment of medication use}

The use of relevant medications post-MI in primary care was established from records of prescriptions. Medication types were classified using British National Formulary (BNF) codes. ${ }^{14}$ The following categories of medications, based on current UK Department of Health guidelines, ${ }^{15}$ were considered: lipidlowering drugs including, but not exclusively, statins (BNF chapter 2.12), beta-blockers (BNF chapter 2.4), ACE inhibitors, including angiotensin receptor blockers (BNF chapters 2.5.5.1 and 2.5.5.2) and anti-platelet drugs including aspirin and clopidogrel (BNF chapter 2.9). At least one record of a prescription from a relevant BNF medication category within 3 months of the date of the patient's MI was taken to indicate that the patient was receiving that category of medication. A 3-month period was used to allow as far as possible time for the patient to have left hospital and used up any prescriptions given in hospital, so that at least one prescription would be required in primary care. A lack of prescription would thus represent the patient not taking the medication, rather than the patient still using medications prescribed in hospital.

\section{Statistical analyses}

The case-fatality rate between 3 months and 3 years after an MI was calculated for every two calendar years from 1991 to 2002 (the year that the MI occurred), standardised by the age-gender distribution of the study population in 2001-2. The average ageadjusted annual change in the case-fatality rate was estimated from Poisson regression of an indicator for death on the calendar year of MI, including age at the time of MI (as a continuous variable) and gender as covariates. Squared terms for age were not significant so were excluded from the final models. Generalised estimating equations with robust standard errors were used in the regression to adjust for variation between different GPs. Follow-up times of patients were censored at 3 years after the date of the MI, or date of loss to follow-up (the earlier of the date the patient left the practice or the practice stopped contributing to THIN) if sooner. Percentage yearly changes in the proportions of people prescribed each medication within 3 months of an MI in primary care were estimated from logistic regression with generalised estimating equations, adjusting for age (as a continuous variable), gender and GP. Differences in the case-fatality and medication trends between men and women were assessed by the addition of an interaction term for calendar time and gender. Analyses were carried out using Stata statistical software (http://www.stata.com).

\section{RESULTS}

In all, 10352 patients from 218 general practices had a record of an MI in THIN between 1991 and 2002, were aged 35 years or over at the time of diagnosis, and were alive for at least 3 months after the MI date and were thus eligible for inclusion in the study. There were 6586 men (64\%) and 3766 women. The mean age at diagnosis of the MI was 67.9 years (SD 12.2 years). Patient characteristics according to calendar year are shown in supplementary table 1 (available online only). Of those 10352 patients who had survived to 3 months, 1547 (14.9\%) died within 3 years; 887 (8.6\%) were censored before the end of the follow-up and 7918 (76.5\%) were censored at 3 years (ie, they had at least 3 years follow-up).

The age-gender standardised 3-year case-fatality rate among 3-month survivors fell from 83.0 (95\% CI 67.9 to 98.1) deaths per 1000 person-years for patients who had an MI in 1991-2 (followed up to 1994-5) to 61.1 (95\% CI 55.8 to 66.4) for patients who had their MI in 2001-2 (followed up to 2004-5) (table 1). This corresponds to an average relative decline in the case-fatality rate of $3.0 \%$ per annum (95\% CI 1.3 to 4.6 , $\mathrm{p}<0.001$ ), adjusting for age and gender, equivalent to a decline of $28.1 \%$ (95\% CI $13.3 \%$ to $40.4 \%$ ) over the 12 years from 1991 to 2002. There was no strong evidence for departure from a uniform trend in the (log) case-fatality rate over time ( $p$ value for a quadratic term in time 0.2). In gender-specific analyses, men showed a consistent and statistically significant decline in case fatality; the average age-adjusted relative decline over the 12 years was $37.0 \%$, 95\% CI 20.4 to $50.1, \mathrm{p}<0.001$. Women showed a smaller, non-significant decline of $14.4 \%, 95 \% \mathrm{CI}$ increase of 11.4 to decline of $34.2, p=0.2$. There was weak evidence that the time trends differed by gender (the test for interaction between gender and calendar time was borderline significant; $p=0.06$ ). 
Table 1 Mortality rates per 1000 person-years during the 3 years following an Ml given survival to 3 months according to calendar year of Ml; standardised to the 2001-2 age-gender distribution in THIN

\begin{tabular}{|c|c|c|c|c|c|c|c|c|c|c|c|c|}
\hline \multirow[b]{2}{*}{$\begin{array}{l}\text { Calendar } \\
\text { year of MI }\end{array}$} & \multicolumn{4}{|c|}{ All MI patients } & \multicolumn{4}{|l|}{ Men } & \multicolumn{4}{|l|}{ Women } \\
\hline & Patients & $\begin{array}{l}\text { Person-years } \\
\text { of follow-up }\end{array}$ & Deaths & $\begin{array}{l}\text { Standardised } \\
\text { mortality rate, per } \\
1000 \text { person-years } \\
(95 \% \mathrm{CI})\end{array}$ & Patients & $\begin{array}{l}\text { Person- } \\
\text { years of } \\
\text { follow-up }\end{array}$ & Deaths & $\begin{array}{l}\text { Standardised } \\
\text { mortality rate, per } \\
1000 \text { person-years } \\
(95 \% \mathrm{CI})\end{array}$ & Patients & $\begin{array}{l}\text { Person- } \\
\text { years of } \\
\text { follow-up }\end{array}$ & Deaths & $\begin{array}{l}\text { Standardised } \\
\text { mortality rate, per } \\
1000 \text { person-years } \\
(95 \% \mathrm{Cl})\end{array}$ \\
\hline $1991-2$ & 604 & 1440.9 & 118 & $83.0(67.9$ to 98.1$)$ & 393 & 945.8 & 66 & 73.0 (55.1 to 90.9$)$ & 211 & 495.2 & 52 & 103.4 (75.1 to 131.6$)$ \\
\hline $1993-4$ & 895 & 2139.5 & 150 & $73.3(61.4$ to 85.2$)$ & 571 & 1380.4 & 93 & 73.9 (58.7 to 89.1$)$ & 324 & 759.2 & 57 & $69.9(51.7$ to 88.1$)$ \\
\hline $1995-6$ & 1141 & 2721.0 & 175 & 67.5 (57.4 to 77.6$)$ & 716 & 1741.8 & 100 & 60.7 (48.7 to 72.6$)$ & 425 & 979.3 & 75 & 77.3 (59.8 to 94.8 ) \\
\hline $1997-8$ & 1582 & 3804.2 & 222 & $62.9(54.5$ to 71.3$)$ & 985 & 2420.0 & 121 & 55.5 (45.5 to 65.4$)$ & 597 & 1384.2 & 101 & $76.0(61.0$ to 90.9$)$ \\
\hline 1999-2000 & 2590 & 6299.7 & 370 & 61.7 (55.4 to 68.0$)$ & 1644 & 4034.2 & 214 & 57.0 (49.3 to 64.6$)$ & 946 & 2265.5 & 156 & 71.7 (60.4 to 83.0$)$ \\
\hline $2001-2$ & 3540 & 8338.0 & 512 & 61.1 (55.8 to 66.4 ) & 2277 & 5478.5 & 286 & $52.0(46.0$ to 58.0$)$ & 1263 & 2859.5 & 226 & 78.6 (68.3 to 88.8$)$ \\
\hline
\end{tabular}

THIN, the Health Improvement Network database; MI, myocardial infarction.

Medication prescribing data were available for all eligible patients. Over the same 12-year period, prescribing in primary care of lipid-lowering drugs in the 3 months following an MI increased dramatically from 3\% of patients in 1991 to $79 \%$ in 2002 , corresponding to an age and gender-adjusted OR of prescribing per annum increase in calendar time of $1.79,95 \% \mathrm{CI}$ 1.73 to 1.85 . Prescribing of beta-blockers increased from $26 \%$ to $68 \%$ (corresponding OR per annum 1.23, 95\% CI 1.20 to 1.26). Prescribing of ACE inhibitors increased from $11 \%$ to $71 \%$ (OR per annum 1.28, 95\% CI 1.26 to 1.30 ) and prescribing of antiplatelet medication increased from $46 \%$ to $86 \%$ (OR per annum $1.20,95 \%$ CI 1.17 to 1.23 ). Prescribing of each of the four evidenced-based medications increased significantly in both men and women (table 2 and figure 1). However, female MI patients consistently received fewer lipid-lowering drugs and beta-blockers than men. The prescribing of lipid-regulating drugs increased in men from 4\% of patients in 1991 to $83 \%$ in 2002, whereas prescribing increased in women from $1 \%$ to $72 \%$. The prescribing of beta-blockers increased from 33\% to $73 \%$ in men compared with an increase from $13 \%$ to $60 \%$ in women. Moreover, the prescribing of lipid-regulating drugs increased at a significantly faster rate in men compared with women $(p=0.009$ for interaction between gender and calendar time).

\section{DISCUSSION}

The longer-term case-fatality rate following an MI (between 3 months and 3 years after the event) fell by 28\% between 1991 and 2002. This significant improvement in longer-term survival following an MI is distinct from previously reported improvements in short-term case fatality. Concurrent large increases in the prescribing of lipid-lowering drugs, beta-blockers, ACE inhibitors and anti-platelet drugs in primary care occurred during the period. Analyses stratified by gender suggested a possible inequality in the survival trends, with men experiencing a greater decline over the study period than women. Men were also more likely to receive lipid-regulating drugs and beta-blockers.

The strengths of this study include the large sample size and nationwide scope of the THIN database, enabling precise estimates of national survival and medication trends. The THIN database is subject to those limitations inherent in all routinely collected data (inconsistencies, incompleteness, variation between GPs). However, death records (the primary outcome) are reliable in $\mathrm{THIN},{ }^{16}$ as are the data on medication prescribing as all medication prescribed to patients will necessarily be recorded in the database. Moreover, it has been shown that THIN is nationally representative in terms of CHD prevalence, when compared with UK Quality and Outcomes Framework (QOF) data ${ }^{17}$ and the incidence of CHD is comparable to that in the UK OResearch Primary Care database. ${ }^{18}$ Diagnostic criteria for MI have changed, particularly as a result of the introduction of troponin. The extent to which the introduction of troponin has influenced trends in longer-term survival is unclear, although correcting for troponin has been shown to have little effect on estimates of trends in short-term survival following MI. ${ }^{19}$

The trends in medication prescribing mirror both reported increases in the overall numbers of prescriptions for these medications dispensed (regardless of indication) in England, ${ }^{1}$ and previously reported trends in the prescribing of these medications in general practice for all forms of CHD in the UK. ${ }^{20} \mathrm{~A}$ previous UK-based study observed similar gender differences in medication use after $\mathrm{MI}^{21}$ There is a lack of data on contemporary trends in longer-term survival following an MI in the UK. An earlier report found longer-term case fatality among 30-day survivors to have fallen significantly by $34 \%$ and $30 \%$ in men and women, respectively, between 1986 and 1995 in Scotland,

Table 2 Trend in medication use according to gender: OR for medication use per annum increase in calendar time for men and women

\begin{tabular}{|c|c|c|c|c|c|c|c|c|c|}
\hline \multirow[b]{2}{*}{ Medication } & \multicolumn{4}{|l|}{ Men } & \multicolumn{4}{|l|}{ Women } & \multirow[b]{2}{*}{$\begin{array}{l}\text { p Value for } \\
\text { gender-time } \\
\text { interaction }\end{array}$} \\
\hline & $\begin{array}{l}\% \text { Receiving } \\
\text { medication } \\
\text { in } 1991\end{array}$ & $\begin{array}{l}\% \text { Receiving } \\
\text { medication } \\
\text { in } 2002\end{array}$ & $\begin{array}{l}\text { OR per annum } \\
\text { increase in } \\
\text { calendar time } \\
(95 \% \mathrm{CI})\end{array}$ & p Value* & $\begin{array}{l}\% \text { Receiving } \\
\text { medication } \\
\text { in } 1991\end{array}$ & $\begin{array}{l}\% \text { Receiving } \\
\text { medication } \\
\text { in } 2002\end{array}$ & $\begin{array}{l}\text { OR per annum } \\
\text { increase in } \\
\text { calendar time } \\
(95 \% \mathrm{CI})\end{array}$ & p Value* & \\
\hline Lipid regulating & 3.9 & 83.1 & $\begin{array}{l}1.83(1.78 \text { to } \\
1.89)\end{array}$ & $<0.001$ & 1.28 & 71.7 & $\begin{array}{l}1.72(1.66 \text { to } \\
1.79)\end{array}$ & $<0.001$ & 0.009 \\
\hline ACE inhibitor & 11.6 & 72.7 & $\begin{array}{l}1.30(1.27 \text { to } \\
1.32)\end{array}$ & $<0.001$ & 10.26 & 67.1 & $\begin{array}{l}1.25(1.22 \text { to } \\
1.28)\end{array}$ & $<0.001$ & 0.03 \\
\hline Anti-platelet & 47.7 & 87.1 & $\begin{array}{l}1.20(1.18 \text { to } \\
1.22)\end{array}$ & $<0.001$ & 42.31 & 83.5 & $\begin{array}{l}1.20(1.17 \text { to } \\
1.23)\end{array}$ & $<0.001$ & $>0.9$ \\
\hline
\end{tabular}


Figure 1 Time trend in the proportion of myocardial infarction (MI) patients prescribed different relevant medications in general practice in the 3 months following the $\mathrm{Ml}$ according to gender.

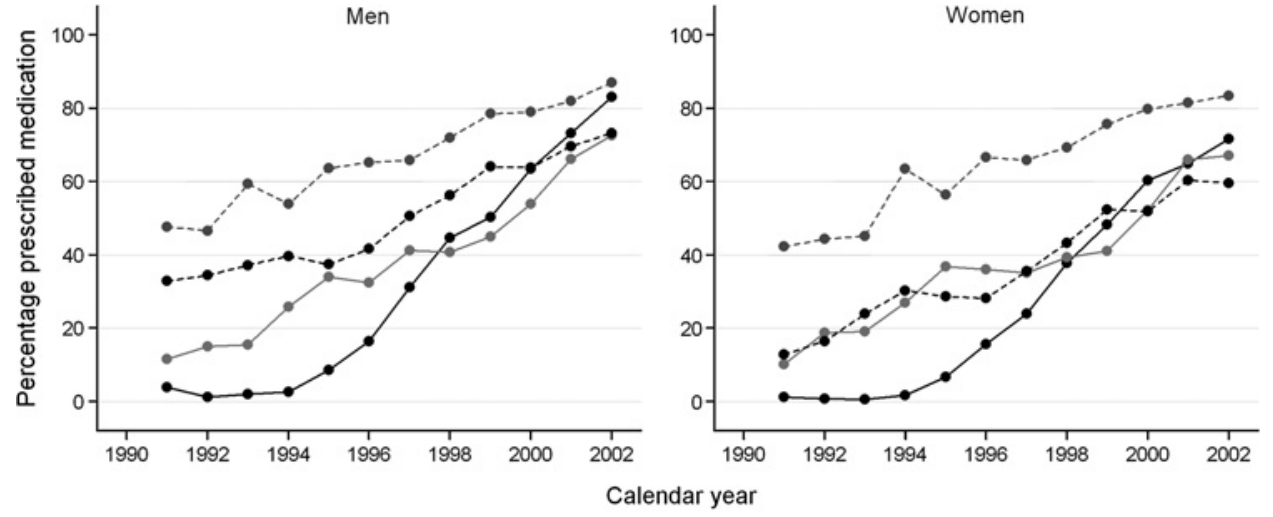

Calendar yea figures comparable with the more recent trends observed in our study. ${ }^{8}$ By comparison, in Minnesota, USA, 3-year mortality odds among 28 -day survivors fell by $32 \%$ in men and by $54 \%$ in women between 1985 and 1995 (the Minnesota Heart Survey). ${ }^{22}$ This contrasts with our study in which women experienced a smaller decline than men, perhaps reflecting the earlier time period and different population. The survey reported concurrent substantial increases in the in-hospital prescribing of betablockers, ACE inhibitors, high-dose heparin and aspirin for both men and women, with women marginally less likely to receive beta-blockers than men, in line with our results. Lipid-lowering drugs were not considered, again reflecting the earlier time period.

\section{Implications}

The results suggest that longer-term case-fatality rates following an $\mathrm{MI}$, in patients who have survived 3 months, have declined by one quarter in 12 years. Over the same period substantial increases in prescribing of relevant evidenced-based medications have occurred. The rapid rise in prescribing of the four medication types reflects the increasing evidence-base for these medications over this period. In particular, statin use was negligible before 1995, a period pre-dating publication of the results of the major statin trials, whereas a rapid increase in statin prescribing followed thereafter. Nevertheless, in the last year of this study, appreciable proportions of MI patients were still not receiving evidenced-based medication (21\% in the case of lipid-lowering drugs, $30 \%$ for beta-blockers and ACE inhibitors) in line with earlier findings. ${ }^{23}$ Even more recently, appreciable proportions of post-MI patients in the UK have not been receiving preventive medications. ${ }^{20}$ The question remains as to what factors may explain the improvement in survival. In terms of short-term case fatality, the WHO MONICA study found that $18 \%$ of the variation in 28-day case fatality trends in an earlier era from 1980 to 1995 between 31 different populations could be explained by differences in the trends in the use of beta-blockers, $31 \%$ by anti-platelet use and $32 \%$ by ACE inhibitors. ${ }^{24}$ The concurrent trends in medication prescribing and survival observed in our study suggests medication prescribing in primary care may also have played a role in the decline in longerterm case fatality. However, medication prescribing alone is unlikely to be a complete explanation. The decline in longerterm case death could also reflect improved intervention in hospital during the acute phase (eg, surgical interventions, rescue coronary angioplasty, thrombolytic agents). In Perth, Western Australia the 12-year case-fatality rate among patients who had an MI in 1991-3 and had already survived one year, was $28 \%$ lower than that of their counterparts who had an MI in 1984-7. ${ }^{25}$ This RR reduction did not persist after adjustment for treatment with thrombolysis, anti-platelets, beta-blockers, ACE inhibitors and lipid-regulating drugs in hospital and prescribed on discharge, as well as coronary artery revascularisation within 12 months of the incident acute MI, suggesting that the increased use of these interventions has contributed to the improvement in survival in this population. In addition, favourable changes in risk factors, in particular a fall in smoking prevalence, ${ }^{1}$ and nutritional improvement, both in the general population and in patients with established cardiovascular disease, are likely to have played a role, as well as improved emergency response, for example through increased cell phone use. $^{26}$

The differences in the trends in survival according to gender lend support to the role of factors in addition to/other than medication prescribing in the trends in survival. Among men, a steady fall in case fatality occurred alongside a steady increase in medication prescribing. However, in contrast, among women, there was no significant improvement in case fatality, despite increases in medication prescribing at almost as fast a rate as for men, implying the presence of other contributing factors (risk factors, surgical interventions) that have improved in men but not in women. In particular, smoking, a key risk factor for MI incidence and mortality, has declined more steeply in men than in women, ${ }^{1}$ and there are reports of middle-aged women having

\section{What is already known on this topic}

Previous studies have demonstrated declines in incidence of heart attacks and in 28-day case fatality in recent years in the UK, which have contributed to the overall decline in coronary heart disease mortality.

- However, little is known about recent trends in longer-term survival after a heart attack.

\section{What this study adds}

Three-year survival among patients who have already survived 3 months has improved significantly between 1991 and 2005, although men may have benefited more than women. 
lower smoking cessation rates than middle-aged men, ${ }^{27}$ which may have contributed to the differential trends in survival. The suggestion that survival among men may have improved at a faster rate than among women is of concern as it implies a widening inequality between men and women, given that women already had a higher 3-year case-fatality rate than men at the start of the study in 1991-2. Further research is needed to validate these findings.

Funding This work was supported by the Medical Research Council National Prevention Research Initiative (grant number G0501307). The funding partners for this award are: British Heart Foundation; Cancer Research UK; Department of Health; Diabetes UK; Economic and Social Research Council; Medical Research Council; Research and Development Office for the Northern Ireland Health and Social Services; Chief Scientist Office, Scottish Executive Health Department and Welsh Assembly government. The authors' work was independent of the funders (the funding source had no involvement).

\section{Competing interests None.}

Ethics approval This study was conducted with the approval of the South East Multi-Centre Research Ethics Committee.

Contributors SLH, PHW, IP, RWM were involved in the study design. SLH undertook the statistical analysis and drafted the initial manuscript and is the guarantor for the paper. PHW, IP, RWM assisted with the analysis. All authors participated in the interpretation of the results, revising of the manuscript and approval of the final draft.

Provenance and peer review Not commissioned; externally peer reviewed.

\section{REFERENCES}

1. British Heart Foundation Statistics Website. Heartstats. http://www.heartstats. org (accessed Jun 2009).

2. Critchley J, Liu J, Zhao D, et al. Explaining the increase in coronary heart disease mortality in Beijing between 1984 and 1999. Circulation 2004;110: 1236-44.

3. Abegunde DO, Mathers CD, Adam T, et al. The burden and costs of chronic diseases in low-income and middle-income countries. Lancet 2007;370: 1929-38.

4. Tunstall-Pedoe $\mathbf{H}$, Kuulasmaa $\mathrm{K}$, Mahonen $\mathbf{M}$, et al. Contribution of trends in survival and coronary-event rates to changes in coronary heart disease mortality: 10year results from 37 WHO MONICA project populations. Monitoring trends and determinants in cardiovascular disease. Lancet 1999;353:1547-57.

5. Lampe FC, Morris RW, Walker M, et al. Trends in rates of different forms of diagnosed coronary heart disease, 1978 to 2000: prospective, population based study of British men. BMJ 2005; 330:1046-50.

6. Unal B, Critchley JA, Capewell S. Modelling the decline in coronary heart disease deaths in England and Wales, 1981-2000: comparing contributions from primary prevention and secondary prevention. BMJ 2005;331:614-19.

7. Hardoon SL, Whincup PH, Lennon LT, et al. How much of the recent decline in the incidence of myocardial infarction in British men can be explained by changes in cardiovascular risk factors? Evidence from a prospective population-based study. Circulation 2008:117:598-604.
8. Capewell S, Livingston BM, Maclntyre K, et al. Trends in case-fatality in 117718 patients admitted with acute myocardial infarction in Scotland. Eur Heart $J$ 2000;21:1833-40.

9. Salomaa V, Ketonen $\mathrm{M}$, Koukkunen $\mathrm{H}$, et al. Decline in out-of-hospital coronary heart disease deaths has contributed the main part to the overall decline in coronary heart disease mortality rates among persons 35 to 64 years of age in Finland: the FINAMI study. Circulation 2003;108:691-6.

10. Bourke A, Dattani H, Robinson M. Feasibility study and methodology to create a quality-evaluated database of primary care data. Inform Prim Care 2004:12:171-7.

11. Maguire A, Blak BT, Thompson M. The importance of defining periods of complete mortality reporting for research using automated data from primary care. Pharmacoepidemiol Drug Saf 2009;18:76-83.

12. Chisholm J. The Read clinical classification. BMJ 1990;300:1092.

13. Office for National Statistics. Key health statistics from general practice 1998. UK: Crown, 2000.

14. British Medical Association and Royal Pharmaceutical Society of Great Britain Joint Formulary Committee. British National Formulary, 53rd edn. UK British Medical Association and Royal Pharmaceutical Society, 2007.

15. Department of Health. Quality and outcomes framework. UK: National Institute for Health and Clinical Excellence, 2004.

16. Hall GC. Validation of death and suicide recording on the THIN UK primary care database. Pharmacoepidemiol Drug Saf 2009;18:120-31.

17. Blak BT, Thompson M, Bourke A. National representativeness and data quality of the Health Improvement Network (THIN) database of primary care information for epidemiological research [abstract]. 9th Annual Conference of the UK Federation of Primary Care Research Organisations. Podium presentation. Liverpool, UK: 2006.

18. Hippisley-Cox J, Coupland C, Vinogradova $Y$, et al. Performance of the QRISK cardiovascular risk prediction algorithm in an independent UK sample of patients from general practice: a validation study. Heart 2008;94:34-9.

19. Salomaa V , Ketonen M, Koukkunen $\mathrm{H}$, et al. The effect of correcting for troponins on trends in coronary heart disease events in Finland during 1993-2002: the FINAMI study. Eur Heart J 2006;27:2394-9.

20. DeWilde S, Carey IM, Richards N, et al. Trends in secondary prevention of ischaemic heart disease in the UK 1994-2005: use of individual and combination treatment. Heart 2008;94:83-8.

21. Hanratty B, Lawlor DA, Robinson MB, et al. Sex differences in risk factors, treatment and mortality after acute myocardial infarction: an observational study. $J$ Epidemiol Community Health 2000;54:912-16.

22. McGovern PG, Jacobs DR Jr, Shahar E, et al. Trends in acute coronary heart disease mortality, morbidity, and medical care from 1985 through 1997: the Minnesota Heart Survey. Circulation 2001;104:19-24.

23. Capewell S, Unal B, Critchley JA, et al. Over 20,000 avoidable coronary deaths in England and Wales in 2000: the failure to give effective treatments to many eligible patients. Heart 2006; $92: 521-3$.

24. Tunstall-Pedoe $\mathbf{H}$, Vanuzzo D, Hobbs M, et al. Estimation of contribution of changes in coronary care to improving survival, event rates, and coronary heart disease mortality across the WHO MONICA project populations. Lancet 2000;355:688-700.

25. Briffa T, Hickling $\mathrm{S}$, Knuiman $\mathrm{M}$, et al. Long term survival after evidence based treatment of acute myocardial infarction and revascularisation: follow-up of population based Perth MONICA cohort, 1984-2005. BMJ 2009;338:b36.

26. Gossage JA, Frith DP, Carrell TW, et al. Mobile phones, in combination with a computer locator system, improve the response times of emergency medical services in central London. Ann R Coll Surg Engl 2008:90:113-16.

27. Rohrbaugh MJ, Shoham V, Dempsey CL. Gender differences in quit support by partners of health-compromised smokers. J Drug Issues 2009:39:329-46. 